\title{
Effect of Chemical Enhancers in Transdermal Permeation of Alfuzosin Hydrochloride
}

\author{
D. Prasanthi and P. K. Lakshmi \\ Department of Pharmaceutics, G. Pulla Reddy College of Pharmacy, Osmania University, Hyderabad, Andhra Pradesh 500028, India \\ Correspondence should be addressed to P. K. Lakshmi, drlakshmisuresh@gmail.com
}

Received 30 October 2012; Accepted 20 November 2012

Academic Editors: H. Arima and C. Saturnino

Copyright ( 2012 D. Prasanthi and P. K. Lakshmi. This is an open access article distributed under the Creative Commons Attribution License, which permits unrestricted use, distribution, and reproduction in any medium, provided the original work is properly cited.

\begin{abstract}
The objective of the present study is to explore the efficient chemical penetration enhancer among the various enhancers available in overcoming the stratum corneum barrier in transdermal delivery of Alfuzosin hydrochloride (AH). The different enhancers were incorporated in 2\% Carbopol gel which was selected as a control and evaluated by in vitro diffusion studies through dialysis membrane and permeation through the rat abdominal skin using Keshary-Chien diffusion cells. All the enhancers increased the release rate through the dialysis membrane when compared with control except oleic acid which decreased the release rate but showed maximum solubility of the drug. Among the various enhancers Transcutol $20 \%$ and tween-20 (2\%) showed the highest cumulative amount $\left(Q_{24}\right)$ of $702.28 \pm 6.97 \mu \mathrm{g} / \mathrm{cm}^{2}$ and $702.74 \pm 7.49 \mu \mathrm{g} / \mathrm{cm}^{2}$, respectively. A flux rate of $31.08 \pm 0.21 \mu \mathrm{g} / \mathrm{cm}^{2} / \mathrm{hr}$ by Transcutol $20 \%$ and $30.38 \pm 0.18 \mu \mathrm{g} / \mathrm{cm}^{2} / \mathrm{hr}$ by tween-20 (2\%) was obtained. Transcutol $20 \%$ showed decreased lag time of $0.13 \pm 0.05 \mathrm{hr}$. The lowest skin content of $342.33 \pm 5.30 \mu \mathrm{g} / \mathrm{gm}$ was seen with oleic acid $2.5 \%$. Maximum enhancement of flux by 3.94-fold was obtained with transcutol $20 \%$. Primary skin irritation studies were performed with rabbit. Histopathological studies of transcutol $20 \%$ showed marked changes such as degeneration and infiltration of mononuclear cells in dermis indicating the effect of transcutol on the skin. Among the different enhancers transcutol is efficient in enhancing transdermal delivery of AH.
\end{abstract}

\section{Introduction}

Alfuzosin hydrochloride (AH), the $\alpha$-adrenoreceptor antagonist, is used for treating benign prostatic hyperplasia. It is indicated for long-term therapy in place of surgery. It undergoes extensive first pass metabolism, has a bioavailability of $60 \%$, half-life (3-5 hour), $\log P(1.6)$, molecular weight (425.9 Daltons) and dose (10 mg per day) [1]. Its physicochemical properties suggest that transdermal drug delivery would be beneficial, but the challenging aspect in transdermal delivery route is permeation through stratum corneum [2].

Several technological approaches have been attempted to overcome this challenge. They are physical approaches, chemical approaches, formulation approaches, and so forth [3].

Chemical approach is the most widely implemented. Chemical enhancers based on their physico-chemical properties enhance permeation through the skin by different mechanisms such as creating diffusion pathways for drug by extracting lipids from the skin, disrupting highly ordered lipid lamellae by partitioning into lipid bilayers, fluidization of lipids, and enhancing the thermodynamic activity of drugs in the formulation. Based on chemical structures of the enhancers they have been classified into water, hydrocarbons, alcohols, acids, amines, amides, esters, surfactants, sulfoxides, terpenes, lipids, and so forth [4-7].

In the present study, enhancers from different classes have been selected based on the literature reported. The enhancers selected are citric acid (organic acid), oleic acid (fatty acid), isopropyl myristate (ester), transcutol (glycol), n-methyl pyrrolidone (pyrrolidones), di-methyl sulfoxide (sulfoxides), tween-20 (non-Ionic surfactant), and $n$-lauroyl sarcosine (anionic surfactant). Each enhancer effect at two different concentrations (with respect to the enhancer reported literature) was evaluated by permeation studies in Carbopol gel formulation using Keshary-Chien diffusion cell. Chemical enhancers have been reported to 
TABLE 1: Composition of base gel (control) formulation.

\begin{tabular}{lc}
\hline Ingredient & $\% \mathrm{w} / \mathrm{w}$ \\
\hline Drug (Alfuzosin hydrochloride) & $1 \%$ \\
Carbopol-980 & $2 \%$ \\
Propanol & $5 \%$ \\
Glycerin & $5 \%$ \\
Triethanolamine & q.s. \\
Methylparaben and propyl paraben & q.s. \\
Distilled water upto & $10 \mathrm{~g}$ \\
\hline
\end{tabular}

cause skin irritation, so primary skin irritation studies have been performed and histopathological studies for optimized enhancer.

The aim of the present study is to optimize the best chemical enhancer for transdermal permeation of $\mathrm{AH}$.

\section{Experimental Details}

2.1. Materials. Alfuzosin hydrochloride (AH) was obtained as a gift sample from Dr. Reddy's Laboratories Ltd (Hyderabad, India). Acrypol-980 was purchased from Corel Pharma Ltd (Ahmedabad, India). Citric acid, oleic acid, isopropyl myristate, dimethyl sulfoxide, $n$-methyl pyrrolidone, $n$ lauroyl sarcosine, transcutol, tween-20, propanol, glycerin and Triethanolamine were purchased from SD Fine-Chem. Ltd., India.

2.2. Preparation of Gels. Appropriate quantities of propanol, glycerin, and water given in Table 1 were mixed together, and the mixture was divided into two equal parts. Acrypol 980 (2\%) was added to one part and soaked for 1 hour. Drug $\mathrm{AH}(1 \%)$ was added to the other part, and this solution was added to acrypol solution. Appropriate amounts of Triethanolamine were added to the solution and mixed until the gel was formed. This was considered as a base gel and taken as control. Chemical enhancer in appropriate concentration according to Table 2 was added to the acrypol solution, to which drug solution was added and allowed to gel by adding Triethanolamine.

2.3. Solubility Studies. Saturated solubility of AH was evaluated by adding an excess of drug to $10 \mathrm{~mL}$ of propanol, glycerin, and water mixture $(5: 5: 90)$ including appropriate quantity of chemical enhancer. The suspension was shaken using a rotary shaker for $24 \mathrm{hr}$ at room temperature; later it was centrifuged for $15 \mathrm{~min}$ at $3000 \mathrm{rpm}$, filtered, and diluted with the vehicle. AH concentration was analyzed by UVVIS double-beam spectrophotometer (Chemito Spectrascan UV2600, India) at $245 \mathrm{~nm}$. The effect of chemical enhancer was determined by enhancement ratio which was calculated by dividing the solubility of $\mathrm{AH}$ in chemical enhancer to the solubility in control (no enhancer).

2.4. In Vitro Diffusion Studies. Diffusion studies of the formulations were performed using locally fabricated KesharyChien diffusion cell of receptor volume $20 \mathrm{~mL}$. The dialysis
TABLE 2: Formulations with different chemical enhancers and respective concentrations used.

\begin{tabular}{llc}
\hline Formulation Code & Enhancer & Concentration \\
\hline CA1 & Citric acid & $1 \%$ \\
CA2 & Citric acid & $2.5 \%$ \\
CA3 & Oleic acid & $2.5 \%$ \\
CA4 & Oleic acid & $5 \%$ \\
CA5 & Isopropylmyristate & $5 \%$ \\
CA6 & Isopropylmyristate & $10 \%$ \\
CA7 & $N$-lauroyl sarcosine & $1 \%$ \\
CA8 & $N$-lauroyl sarcosine & $2 \%$ \\
CA9 & Tween-20 & $1 \%$ \\
CA10 & Tween-20 & $2 \%$ \\
CA11 & Transcutol & $10 \%$ \\
CA12 & Transcutol & $20 \%$ \\
CA13 & Dimethyl sulfoxide & $5 \%$ \\
CA14 & Dimethyl sulfoxide & $10 \%$ \\
CA15 & $N$-methylpyrrolidone & $5 \%$ \\
CA16 & $N$-methylpyrrolidone & $10 \%$ \\
\hline
\end{tabular}

membrane was mounted between the donor and receptor compartments. $500 \mathrm{mg}$ of gel formulation was applied uniformly to the dialysis membrane and the compartment clamped together. The receptor compartment was filled with phosphate buffer saline $\mathrm{pH} 7.4$, and the hydrodynamics in the receptor compartment were maintained by stirring with a magnetic bead. At predetermined time intervals $1 \mathrm{~mL}$ of samples was withdrawn, and an equal volume of buffer was replaced. The samples were analysed after appropriate dilution for drug content spectrophotometrically at $245 \mathrm{~nm}$.

$\mathrm{AH}$ release rate, $k$, was determined from the slope of the amount of drug released per unit area versus the square root of time [8].

2.5. Ex Vivo Permeation Studies. The experimental protocol was approved by the institutional animal ethics committee (IAEC).

Male Wistar rats (150-180 g) were sacrificed by excessive ether anesthesia, and abdominal hair was removed using an animal hair clipper (Aesculap, Germany). Skin was excised and observed for any cuts/wounds. The fat adhering dermis was removed using a scalpel, and it was washed under tap water. The skin was stored at $-20^{\circ} \mathrm{C}$ and used within a week.

Locally fabricated Keshary-Chien diffusion cells with area $4.9 \mathrm{~cm}^{2}$ and $20 \mathrm{~mL}$ receptor volume were used for permeation studies. The thawed rat skin was mounted onto diffusion cell such that stratum corneum was facing donor compartment and dermis was in constant contact with receptor solution. $500 \mathrm{mg}$ of gel was applied to the stratum corneum, and the hydrodynamics in the receptor compartment were maintained by stirring on magnetic stirrer at $600 \mathrm{rpm}$ (Remi Equipments Ltd). $1 \mathrm{~mL}$ of sample was withdrawn at predetermined time intervals for $24 \mathrm{hrs}$, and drug content was analyzed by UV-VIS double-beam 
spectrophotometer (Chemito spectrascan UV2600, India) at $245 \mathrm{~nm}$.

After $24 \mathrm{hr}$ study drug retained in the skin was determined. For skin content studies, after study the skin was removed, washed with methanol, and homogenized. The mixture was centrifuged at $7000 \mathrm{rpm}$ for $30 \mathrm{~min}$, filtered, and analysed for drug content spectrophotometrically at $245 \mathrm{~nm}$.

2.6. Skin Irritation Studies. The institutional animal ethical committee approved the experimental protocol. A primary skin irritation test was performed since skin is the vital organ through which the drug is transported. The test was carried out on three healthy rabbits weighing between 1.5 and $2 \mathrm{~kg}$. The test was conducted on an unbraided skin of rabbits. Before placing the formulations, the unbraided skin was cleaned with rectified spirit. The control formulation was placed on the left dorsal surface of each rabbit, whereas the test formulation (with drug and chemical enhancer) was placed on the right dorsal surface of the same rabbits, and the other rabbit was kept as control. The formulations were removed after $24 \mathrm{~h}$, and the skin was examined for erythema/edema.

2.7. Histopathological Studies. Histopathological studies were conducted according to the protocol approved by the institutional animal ethical committee (IAEC). The control gel formulations (placebo) and optimized gel formulations (with chemical enhancer) were applied to Wistar rats (with hair shaven at application sites) for $6 \mathrm{hrs}$. Then the animal was sacrificed, and skin was excised and stored at $50 \%$ neutral formalin solution. It was further subjected to histological processing such as dehydration and rehydration with alcohols, staining with haematoxylin-eosin dye, paraffin blocks, and slide preparation. $\mathrm{H} \& \mathrm{E}$ slides were evaluated using dark-light microscope by a blinded assessor.

2.8. Data Analysis. The cumulative amount permeated in $24 \mathrm{hrs}\left(Q_{24}\right)$ was calculated from permeation studies. Flux $\left(J_{\text {ss }}\right)$ was calculated from the slope of the curve on plotting $Q_{24}$ versus time, and X-intercept of a straight-line portion of the curve is lag time. Flux divided by the donor concentration resulted in an apparent permeability coefficient $(K p)$. Means and standard deviation were calculated using Microsoft Excel 2003. The experiments were performed in triplicate $(n=3)$, and data were subjected to one-way ANOVA at a significance level of $P \leq 0.05$ using MINITAB 16 software (Minitab Inc., PA, USA).

\section{Results and Discussions}

The present investigation was carried out to optimize the chemical penetration enhancers for delivering effective therapeutic amounts of AH through the skin. AH base gel (control) was prepared according to the composition in Table 1. Chemical penetration enhancers were incorporated in the gel according to the concentration of the enhancers given in Table 2 .

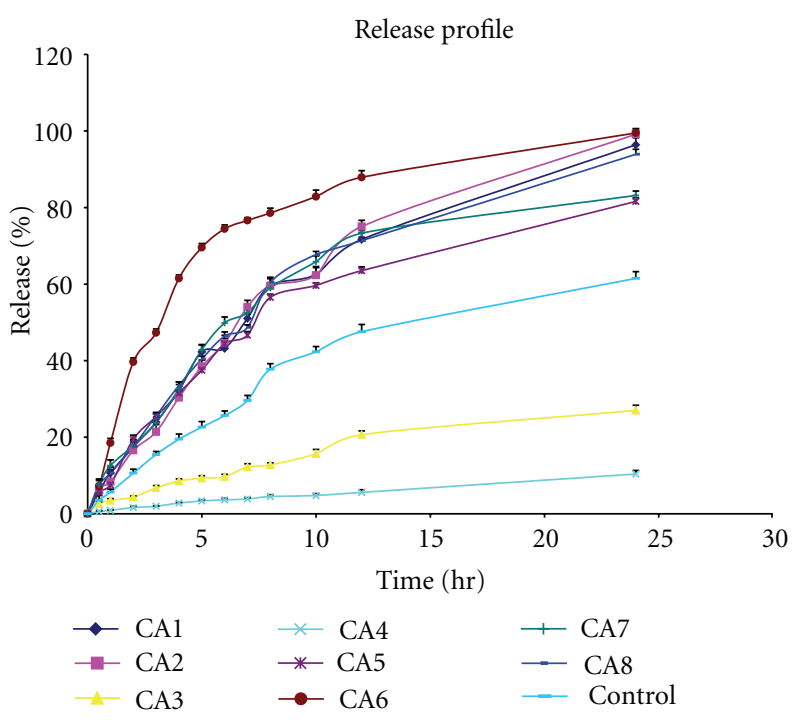

FIGURE 1: Release profile of formulations CA1 to CA8 in comparison to control through dialysis membrane.

Solubility of $\mathrm{AH}$ in a solvent mixture (propanol: glycerine: water $(5: 5: 90))$ of control gel was evaluated and represented as unity. Enhancement of solubility of $\mathrm{AH}$ by different enhancers is listed in Table 3. Maximum enhancement of solubility was shown by oleic acid $2.5 \%$ $(42.92 \pm 0.65 \mathrm{mg} / \mathrm{mL})$ by 1.83 -fold, followed by transcutol $20 \%(42.60 \pm 1.15 \mathrm{mg} / \mathrm{mL})$ by 1.82 -fold, $n$-methyl pyrrolidone $10 \%(40.61 \pm 1.32 \mathrm{mg} / \mathrm{mL})$ by 1.73 -fold, transcutol $10 \%(38.27 \pm 1.03 \mathrm{mg} / \mathrm{mL})$ by 1.63 -fold, dimethyl sulfoxide $5 \%(35.88 \pm 0.87 \mathrm{mg} / \mathrm{mL})$ by 1.53 -fold, $n$-lauroyl sarcosine $2 \%(35.32 \pm 1.02 \mathrm{mg} / \mathrm{mL})$ by 1.51 -fold, isopropyl myristate $10 \%(33.53 \pm 1.10 \mathrm{mg} / \mathrm{mL})$ by 1.43 -fold, and $n$-methyl pyrrolidone $5 \%(32.74 \pm 1.15 \mathrm{mg} / \mathrm{mL})$ by 1.40 -fold. Solubility was decreased by tween-20 (1\%) when compared with control, but showed a maximum release rate $396.36 \pm$ $0.53 \mu \mathrm{g} / \mathrm{cm}^{2} / \mathrm{hr}^{1 / 2}$ ) through dialysis membrane. Oleic acid $2.5 \%$ which showed maximum enhancement of solubility decreased the release rate $\left(58.95 \pm 0.39 \mu \mathrm{g} / \mathrm{cm}^{2} / \mathrm{hr}^{1 / 2}\right)$ when compared with control.

The diffusion studies were performed on locally fabricated keshary-chein diffusion cell through dialysis membrane. The percentage release in 24 hrs by different enhancers when compared with control is shown in Figures 1 and 2. The release rate of these formulations is given in Table 3 . Formulation CA9 containing tween-20 (1\%) showed the maximum release $\left(396.36 \pm 0.53 \mu \mathrm{g} / \mathrm{cm}^{2} / \mathrm{hr}^{1 / 2}\right)$ in $6 \mathrm{hrs}$ only, and CA13 formulation containing dimethyl sulfoxide $5 \%$ showed the maximum release $\left(324.07 \pm 0.52 \mu \mathrm{g} / \mathrm{cm}^{2} / \mathrm{hr}^{1 / 2}\right)$ in $12 \mathrm{hrs}$ only. Formulations CA3 and CA4 containing oleic acid $2.5 \%$ and $5 \%$, respectively, decreased release $\left(58.95 \pm 0.39 \mu \mathrm{g} / \mathrm{cm}^{2} / \mathrm{hr}^{1 / 2}, 20.81 \pm 0.28 \mu \mathrm{g} / \mathrm{cm}^{2} / \mathrm{hr}^{1 / 2}\right)$ of drug when compared to control. Each enhancer was formulated in two different concentrations, and with an increase in concentration, increase in release rate was observed except with oleic acid, tween-20, and dimethyl sulfoxide where release rate was decreased with increase in concentration. 


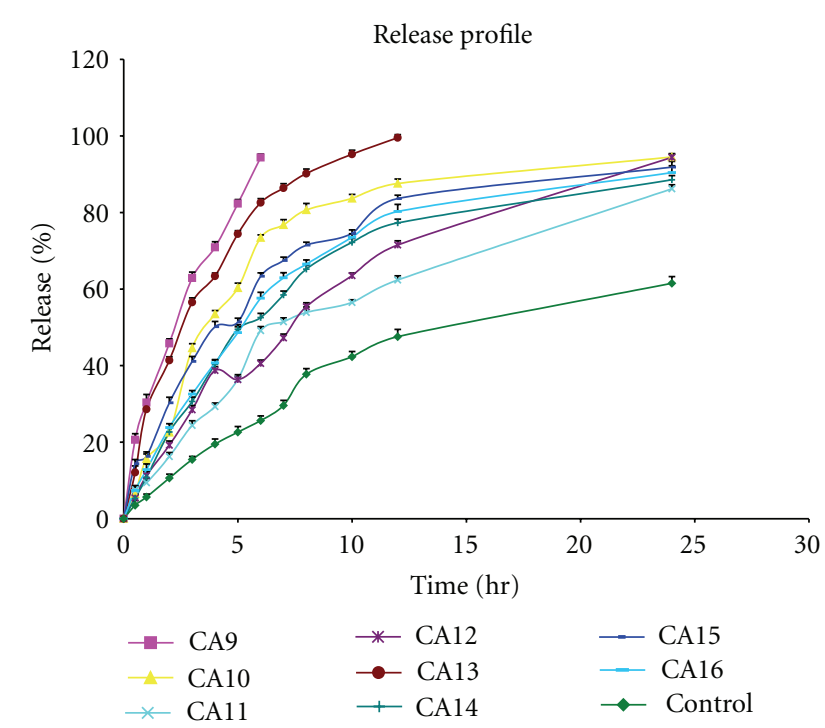

Figure 2: Release profile of formulations CA9 to CA16 in comparison to control through dialysis membrane.

Permeation studies using rat abdominal skin were performed and the parameters calculated (Table 4). Permeation profile is shown in Figures 3 and 4 in comparison with control. Maximum cumulative amount permeated was seen with formulations CA12 $\left(702.28 \pm 6.97 \mu \mathrm{g} / \mathrm{cm}^{2}\right)$, and CA10 $\left(702.74 \pm 7.49 \mu \mathrm{g} / \mathrm{cm}^{2}\right)$ containing transcutol $20 \%$ and tween-20 (2\%), respectively, followed by isopropyl myristate $10 \%\left(589.89 \pm 5.05 \mu \mathrm{g} / \mathrm{cm}^{2}\right), n$-lauroyl sarcosine $2 \%\left(566.02 \pm 4.71 \mu \mathrm{g} / \mathrm{cm}^{2}\right)$, tween-20 (1\%) (518.65 \pm $\left.6.69 \mu \mathrm{g} / \mathrm{cm}^{2}\right)$, and transcutol $10 \%\left(507.26 \pm 6.73 \mu \mathrm{g} / \mathrm{cm}^{2}\right)$.

Transcutol 20\% showed, the lowest lag time of $0.13 \pm$ $0.05 \mathrm{hr}$ followed by tween-20 (2\%) $(0.30 \pm 0.20 \mathrm{hr}), n$ methyl pyrrolidone $10 \%(0.43 \pm 0.15 \mathrm{hr})$, transcutol $10 \%$ $(0.46 \pm 0.15 \mathrm{hr})$, and dimethyl sulfoxide $5 \%(0.50 \pm 0.10 \mathrm{hr})$ when compared with control $(2.96 \pm 0.35 \mathrm{hr})$. After $24 \mathrm{hrs}$ of study, drug retained in skin was determined, and the lowest skin content was obtained with oleic acid $2.5 \%(342.33 \pm 05.30 \mu \mathrm{g} / \mathrm{gm})$, transcutol 20\% (355.93 \pm $8.60 \mu \mathrm{g} / \mathrm{gm})$, dimethyl sulfoxide $10 \%(561.93 \pm 9.26 \mu \mathrm{g} / \mathrm{gm})$, and $n$-lauroyl sarcosine $2 \%(567.82 \pm 11.96 \mu \mathrm{g} / \mathrm{gm})$ when compared with control $(1246.79 \pm 10.63 \mu \mathrm{g} / \mathrm{gm})$. The flux was enhanced by enhancers when compared with control ( $7.59 \pm$ $\left.0.27 \mu \mathrm{g} / \mathrm{cm}^{2} / \mathrm{hr}\right)$ by 3.94 -fold by transcutol $20 \%(31.08 \pm$ $0.21 \mu \mathrm{g} / \mathrm{cm}^{2} / \mathrm{hr}$ ) followed by 3.85 -fold by tween-20 (2\%). All the enhancers enhanced the permeation of $\mathrm{AH}$ when compared to control. Even oleic acid which decreased the release rate enhanced permeation of $\mathrm{AH}$ through rat skin.

Skin-irritation studies were performed on rabbits with higher concentration of each enhancer used, according to the protocol approved by institutional animal ethical committee. The effect has been graded based on the extent of erythema caused as 0 -no erythema, 1 -very slight erythema (barely perceptible), 2-well-defined erythema, and 3-moderateto-severe erythema [9], and the results are given in Table 5.

\subsection{Effect of Chemical Enhancers}

3.1.1. Effect of Organic Acid. Citric acid 1\% and 2.5\% increased the solubility of AH by 1.13- and 1.25-fold, respectively. Increase in concentration increased release rate through dialysis membrane. Permeation also increased linearly with concentration $(P<0.000)$. No signs of skin irritation were observed. $\mathrm{AH}$ permeability through rat skin was enhanced by 2.05 - and 1.51 -fold by citric acid $2.5 \%$, and $1 \%$, respectively. Citric acid $1 \%$ enhanced permeation of indapamide by 3.47 , fold across the rat abdominal skin by formation of an ion pair [10].

3.1.2. Effect of Fatty Acids and Esters. Fatty acid and oleic acid at concentrations $2.5 \%$ and $5 \%$ were used. Maximum solubility of AH was obtained with $2.5 \%$ but the release rate was decreased. Permeability was enhanced, but with an increase in concentration, enhancement decreased $(P<$ $0.000)$. Maximum lag time $(2.70 \pm 0.20 \mathrm{hr}$ with $2.5 \%$ and $2.33 \pm 0.15 \mathrm{hr}$ with $5 \%$ ) was seen with oleic acid. The decrease in release rate when compared to control can be due to the mechanism of fatty acids, such as partitioning into lipid bilayers, that is, stratum corneum and forming lipophilic complexes with drugs [3]. The release rate was measured through the dialysis membrane where it is not impregnated with lipids, and hence even though the solubility is increased, there is a decrease in release rate. The inverse relationship of concentration and enhancement was observed which has also been reported with meloxicam gel [11]. Pretreatment of tissue with fatty acids has been reported to decrease the lag time and enhance drug retainment in skin [12]. In the experimental condition pretreatment was not done, and hence increase in lag time might have resulted.

Incorporation of the most widely studied ester isopropyl myristate at $5 \%$ and $10 \%$ showed enhanced solubility, release rate through a dialysis membrane, and permeation across the rat abdominal skin. The enhancement was linear with concentration $(P<0.000)$. They are known to enhance permeation by partitioning themselves in the ordered lipid domains of the stratum corneum [7, 13]. A similar effect was also observed with nicorandil [14] and diclofenac sodium [8] wherein shortening of lag time was also reported. In the present study also similar effect of decreased lag time $(1.76 \pm 0.15 \mathrm{hr}$ with $5 \%$ and $0.76 \pm 0.15 \mathrm{hr}$ with $10 \%)$ with an increase in concentration was seen. No sign of skin irritation was observed with oleic acid and isopropyl myristate.

3.1.3. Effect of Surfactants. Anionic and nonionic surfactants are more widely studied [3] in evaluating penetration enhancement abilities. In the present study $n$-lauroyl sarcosine, an anionic surfactant, and tween-20, a nonionic surfactant have been studied at two concentrations 1\% and $2 \%$. With anionic surfactant a linear relation was observed between concentration and solubility, release rate and permeation through the rat abdominal skin $(P<0.000)$. Well-defined erythema was observed when tested on rabbit skin. 
TABLE 3: Solubility of AH in different chemical enhancers and release rate of formulations through dialysis membrane.

\begin{tabular}{|c|c|c|c|}
\hline Formulation code & Solubility $(\mathrm{mg} / \mathrm{mL})$ & $\mathrm{ER}_{\text {sol }}{ }^{\mathrm{b}}$ & Release rate $\left(\mu \mathrm{g} / \mathrm{cm}^{2} / \mathrm{hr}^{1 / 2}\right)$ \\
\hline Control & $23.34 \pm 1.07$ & 1 & $143.41 \pm 0.10$ \\
\hline CA1 & $26.42 \pm 1.05$ & 1.13 & $223.37 \pm 0.21$ \\
\hline CA2 & $29.34 \pm 1.12$ & 1.25 & $230.99 \pm 0.05$ \\
\hline CA3 & $42.92 \pm 0.65$ & 1.83 & $58.95 \pm 0.39$ \\
\hline CA4 & $27.65 \pm 1.02$ & 1.18 & $20.81 \pm 0.28$ \\
\hline CA5 & $25.44 \pm 1.08$ & 1.08 & $194.75 \pm 0.21$ \\
\hline CA6 & $33.53 \pm 1.10$ & 1.43 & $241.47 \pm 0.08$ \\
\hline CA7 & $30.86 \pm 1.43$ & 1.32 & $205.35 \pm 0.43$ \\
\hline CA8 & $35.32 \pm 1.02$ & 1.51 & $219.79 \pm 0.25$ \\
\hline CA9 & $20.92 \pm 1.12$ & 0.89 & $396.36 \pm 0.53$ \\
\hline CA10 & $28.67 \pm 1.05$ & 1.22 & $254.44 \pm 0.18$ \\
\hline CA11 & $38.27 \pm 1.03$ & 1.63 & $197.61 \pm 0.37$ \\
\hline CA12 & $42.60 \pm 1.15$ & 1.82 & $214.94 \pm 0.25$ \\
\hline CA13 & $35.88 \pm 0.87$ & 1.53 & $324.07 \pm 0.52$ \\
\hline CA14 & $26.90 \pm 0.93$ & 1.15 & $221.29 \pm 0.32$ \\
\hline CA15 & $32.74 \pm 1.15$ & 1.40 & $219.26 \pm 0.24$ \\
\hline CA16 & $40.61 \pm 1.32$ & 1.73 & $224.50 \pm 0.29$ \\
\hline
\end{tabular}

a Solubility is the solubility of $\mathrm{AH}$ in the hydrogel solvent mixture at $25^{\circ} \mathrm{C} .{ }^{\mathrm{b}} \mathrm{ER}_{\text {sol }}$ is enhancement ratio of AH solubility over control solubility. Values represent mean \pm S.D $(n=3)$.

TABLE 4: Permeation parameters of AH formulations.

\begin{tabular}{|c|c|c|c|c|c|c|}
\hline $\begin{array}{l}\text { Formulation } \\
\text { code }\end{array}$ & $Q_{24}\left(\mu \mathrm{g} / \mathrm{cm}^{2}\right)$ & Flux $\left(\mu \mathrm{g} / \mathrm{cm}^{2} / \mathrm{hr}\right)$ & $\begin{array}{l}\text { Permeability coefficient } \\
\qquad\left(\times 10^{-03}\right)(\mathrm{cm} / \mathrm{hr})\end{array}$ & Lag time (hr) & Skin content $(\mu \mathrm{g} / \mathrm{gm})$ & ER \\
\hline Control & $182.84 \pm 7.81$ & $7.59 \pm 0.27$ & $1.51 \pm 0.05$ & $2.96 \pm 0.35$ & $1246.79 \pm 10.63$ & 1 \\
\hline CA1 & $274.17 \pm 6.17$ & $11.91 \pm 0.16$ & $2.38 \pm 0.03$ & $1.06 \pm 0.15$ & $981.20 \pm 05.65$ & 1.51 \\
\hline CA2 & $365.05 \pm 4.78$ & $16.16 \pm 0.22$ & $3.23 \pm 0.04$ & $2.26 \pm 0.15$ & $754.61 \pm 16.47$ & 2.05 \\
\hline CA3 & $307.43 \pm 6.40$ & $14.24 \pm 0.19$ & $2.84 \pm 0.03$ & $2.70 \pm 0.20$ & $342.33 \pm 05.30$ & 1.80 \\
\hline CA4 & $257.73 \pm 6.02$ & $12.56 \pm 0.19$ & $2.51 \pm 0.03$ & $2.33 \pm 0.15$ & $1032.36 \pm 07.93$ & 1.59 \\
\hline CA5 & $267.59 \pm 6.66$ & $12.51 \pm 0.19$ & $2.50 \pm 0.03$ & $1.76 \pm 0.15$ & $1133.28 \pm 11.33$ & 1.58 \\
\hline CA6 & $589.89 \pm 5.05$ & $25.34 \pm 0.09$ & $5.06 \pm 0.01$ & $0.76 \pm 0.15$ & $955.63 \pm 09.41$ & 3.21 \\
\hline CA7 & $383.55 \pm 7.03$ & $17.08 \pm 0.21$ & $3.41 \pm 0.04$ & $0.80 \pm 0.10$ & $676.34 \pm 09.68$ & 2.16 \\
\hline CA8 & $566.02 \pm 4.71$ & $25.88 \pm 0.08$ & $5.17 \pm 0.01$ & $1.10 \pm 0.20$ & $567.82 \pm 11.96$ & 3.28 \\
\hline CA9 & $518.65 \pm 6.69$ & $22.39 \pm 0.20$ & $4.47 \pm 0.04$ & $1.23 \pm 0.15$ & $713.82 \pm 12.33$ & 2.84 \\
\hline CA10 & $702.74 \pm 7.49$ & $30.38 \pm 0.18$ & $6.07 \pm 0.03$ & $0.30 \pm 0.20$ & $592.20 \pm 08.54$ & 3.85 \\
\hline CA11 & $507.26 \pm 6.73$ & $22.67 \pm 0.18$ & $4.53 \pm 0.03$ & $0.46 \pm 0.15$ & $651.33 \pm 09.00$ & 2.87 \\
\hline CA12 & $702.28 \pm 6.97$ & $31.08 \pm 0.21$ & $6.21 \pm 0.04$ & $0.13 \pm 0.05$ & $355.93 \pm 08.60$ & 3.94 \\
\hline CA13 & $351.39 \pm 6.95$ & $14.87 \pm 0.14$ & $2.97 \pm 0.02$ & $0.50 \pm 0.10$ & $877.00 \pm 08.28$ & 1.88 \\
\hline CA14 & $303.85 \pm 6.08$ & $12.99 \pm 0.15$ & $2.59 \pm 0.03$ & $0.83 \pm 0.15$ & $561.93 \pm 09.26$ & 1.64 \\
\hline CA15 & $314.25 \pm 4.80$ & $14.79 \pm 0.09$ & $2.95 \pm 0.01$ & $1.33 \pm 0.15$ & $875.97 \pm 08.61$ & 1.87 \\
\hline CA16 & $490.75 \pm 6.04$ & $21.38 \pm 0.08$ & $4.27 \pm 0.01$ & $0.43 \pm 0.15$ & $687.58 \pm 08.30$ & 2.71 \\
\hline
\end{tabular}

$Q_{24}$ is the cumulative amount permeated in $24 \mathrm{hrs}$; ER is an enhancement ratio of the flux of chemical enhancers over control. Values represent mean \pm S.D $(n=3)$.

With nonionic surfactant tween-20, with $1 \%$, the solubility decreased when compared with control, but with $2 \%$ solubility was enhanced by 1.22 fold. The release rate was increased by $1 \%$ such that the maximum amount of AH diffused within 6 hrs but as the concentration increased the release rate decreased. A linear effect was observed with concentration and permeation through the rat abdominal skin $(P<0.000)$. The results were in accordance with studies reported with meloxicam gel where permeability through IPM-saturated cellulose membrane decreased as a tween-20 increased, and no changes in overall permeability effect through human cadaver skin were observed [11]. Tween-20 caused very slight erythema when tested on rabbit skin. In general surfactants act by swelling of keratinocytes, 


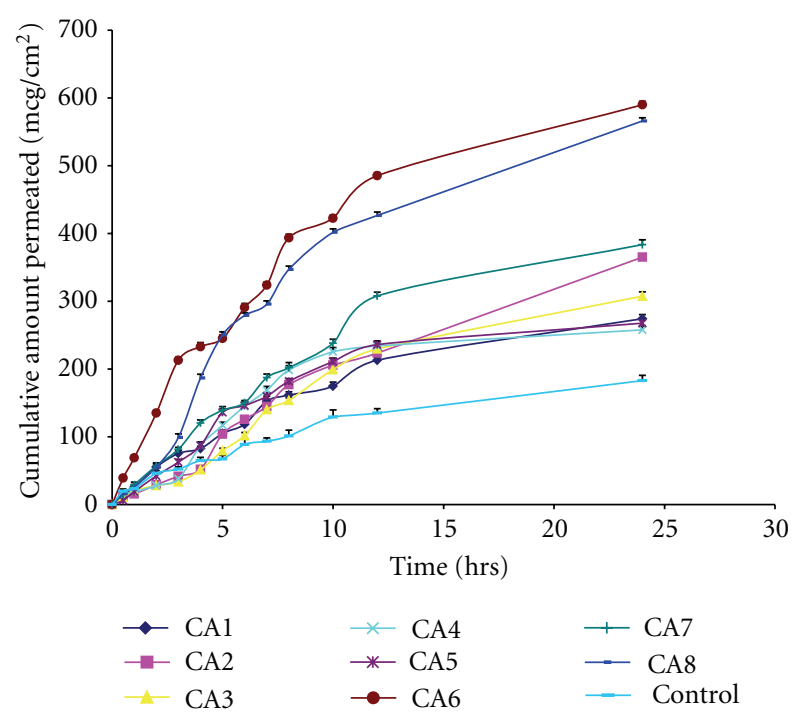

Figure 3: Permeation profile of formulations CA1 to CA8 in comparison with control through the rat abdominal skin.

TABLE 5: Skin irritation effect of different chemical enhancers.

\begin{tabular}{lc}
\hline Chemical enhancer with concentration & Skin irritation \\
\hline Citric acid $(2.5 \%)$ & 0 \\
Oleic acid (5\%) & 0 \\
Isopropyl myristate $(10 \%)$ & 0 \\
$N$-lauroyl sarcosine (2\%) & 2 \\
Tween-20 (2\%) & 1 \\
Transcutol (20\%) & 1 \\
Dimethyl sulfoxide $(10 \%)$ & 2 \\
$N$-methyl pyrrolidone $(10 \%)$ & 3 \\
\hline
\end{tabular}

disruption of lamellar structure of lipids, denaturation of keratin, dissolution of skin lipids, and fluidization of lipid bilayers [15].

3.1.4. Effect of Glycols. The effect of diethyleneglycol monoethylether (transcutol) on the permeation of AH was investigated. Transcutol is known as a powerful solubilising agent and is an attractive penetration enhancer due to its nontoxicity, miscibility with polar and nonpolar solvents and biocompatibility with the skin [16]. In the present study transcutol enhanced solubility by 1.82 fold and release rate was also enhanced as the percentage increased. Permeation was enhanced by 3.94 fold, and it was significant with increase in concentration $(P<0.000)$. When compared with other enhancers, maximum solubility and maximum permeation through rat abdominal skin were observed. Very slight erythema of rabbit's skin was observed from skin irritation studies. The linear relation of transcutol percentage and permeation was also observed in clonazepam transdermal permeation where the enhancement is reported due to solubilising properties of transcutol and its ability to increase drug cutaneous retention [16].

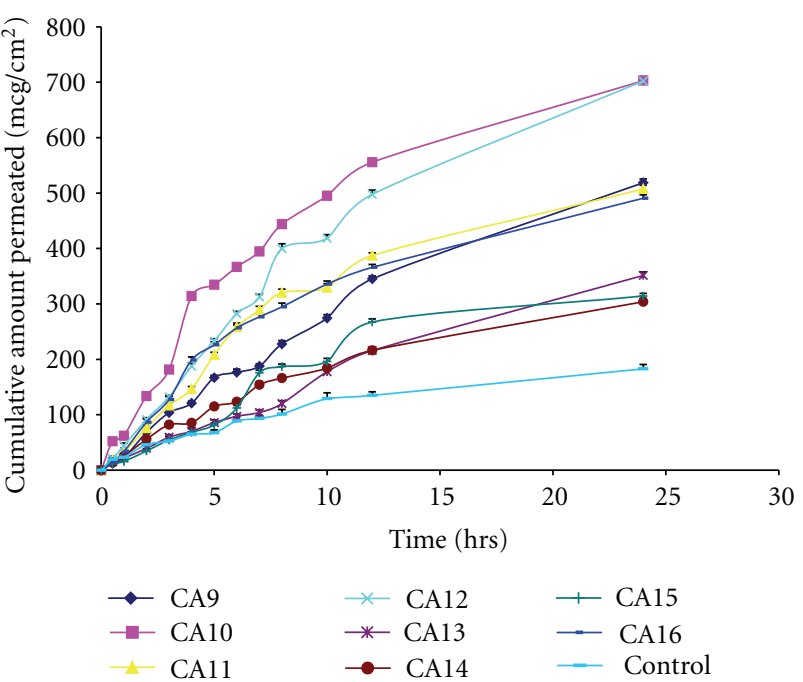

Figure 4: Permeation profile of formulations CA9 to CA16 in comparison with control through the rat abdominal skin.

3.1.5. Effect of Sulphoxides. Incorporation of dimethyl sulfoxide $5 \%$ enhanced the solubility, release rate, and permeability coefficient whereas with increasing the concentration to $10 \%$, the effect decreased $(P<0.001)$. The similar effect of decreased permeation with $10 \%$ dimethyl sulfoxide was observed with transdermal delivery of aspirin [17]. Dimethyl sulfoxide is known to enhance permeation at concentrations exceeding $60 \%$, and it is also known to cause erythema at higher concentrations [18]. So, lesser concentrations were selected for investigating its effect. $5 \%$ were found to enhance permeation better than $10 \%$, and it caused well-defined erythema. Sulfoxides enhance permeation by different mechanisms such as extraction of skin lipids and denaturation of stratum corneum proteins [19].

3.1.6. Effect of Pyrrolidones. $N$-methyl pyrrolidone, the most extensively investigated compound of this group, was studied in two concentrations $5 \%$ and $10 \%$. Solubility, release rate, and permeability coefficient were enhanced as the percentage increased $(P<0.000)$. Moderate-to-severe erythema was observed even with lower concentration. Pyrrolidones are known to enhance permeation by partitioning into the stratum corneum and altering the solvent nature of the membrane [20].

Among the different chemical enhancers used formulation CA12 containing transcutol $20 \%$ was optimized as maximum enhancement of permeation by 3.94 fold was obtained.

Histopathology studies of the optimized enhanced formulation (CA12) containing transcutol 20\% and placebo gel (control without enhancer) were performed and compared with control (Figure 5) according to the protocol approved by institutional animal ethical committee. When compared with control $\mathrm{H}$ \& $\mathrm{E}$ slides of placebo gel showed severe congestion, hemorrhage, and degeneration in dermis with moderate-to-severe inflammatory changes and edema in the 


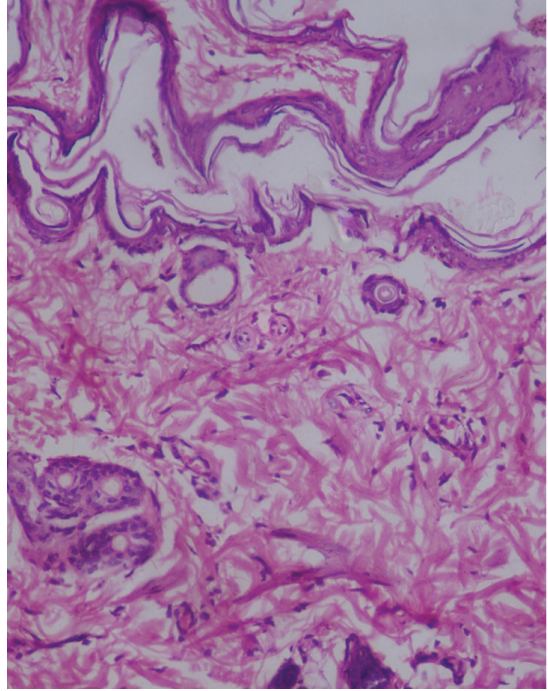

Control

(a)

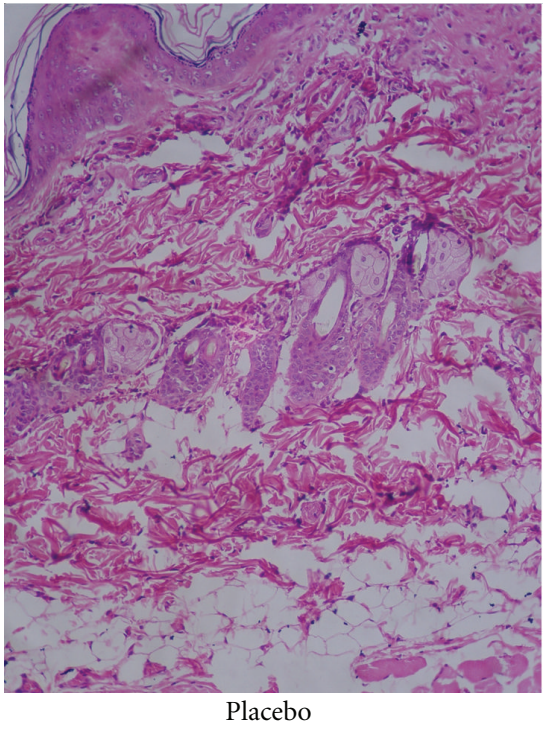

(b)

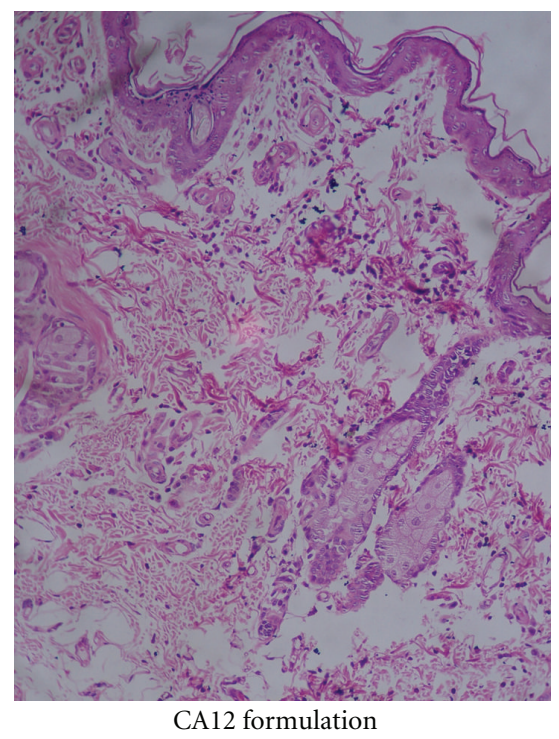

(c)

Figure 5: Histological slides of control (without any formulation), placebo (control gel), and CA12 (optimised chemical enhancer formulation).

epidermis. Slides of optimized formulation showed congestion, degeneration, and inflammatory cells predominantly mononuclear cell infiltration in the dermis.

Changes in the skin treated with placebo gel when compared with control showed that carbopol permeates or enhances permeation. With CA12 formulation major changes in the dermis were observed which can be attributed to the action of transcutol.

\section{Conclusion}

In transdermal delivery, due to excellent barrier function of skin, the choice of an efficient chemical penetration enhancer is important. In the present study among the various enhancers evaluated transcutol $20 \%$ showed maximum permeation and the enhancement appears to be related to solubilising properties of transcutol which is shown by enhancement of AH solubility by 1.82 fold. Histopathological studies further conformed its enhancement by degenerative changes in the dermis.

\section{References}

[1] A. C. Moffat, M. D. Osselton, B. Widdop, and J. Watts, Eds., Clarke's Analysis of Drugs and Poisons, Pharmaceutical Press, London, UK.

[2] A. C. Williams and B. W. Barry, "Penetration enhancers," Advanced Drug Delivery Reviews, vol. 56, no. 5, pp. 603-618, 2004.

[3] P. Karande and S. Mitragotri, "Enhancement of transdermal drug delivery via synergistic action of chemicals," Biochimica et Biophysica Acta, vol. 1788, no. 11, pp. 2362-2373, 2009.

[4] P. Karande, A. Jain, K. Ergun, V. Kispersky, and S. Mitragotri, "Design principles of chemical penetration enhancers for transdermal drug delivery," Proceedings of the National Academy of Sciences of the United States of America, vol. 102, no. 13, pp. 4688-4693, 2005.

[5] B. W. Barry, "Breaching the skin's barrier to drugs," Nature Biotechnology, vol. 22, no. 2, pp. 165-167, 2004.

[6] B. W. Barry, "Lipid-protein-partitioning theory of skin penetration enhancement," Journal of Controlled Release, vol. 15, no. 3, pp. 237-248, 1991.

[7] N. Buyuktimkin, S. Buyuktimkin, and J. H. Rytting, "Chemical means of transdermal drug permeation enhancement," in Transdermal and Topical Drug Delivery Systems, T. K. Ghosh, W. R. Pfister, and S. Yum, Eds., Informa Health Care, 1997.

[8] A. Arellano, S. Santoyo, C. Martín, and P. Ygartua, "Influence of propylene glycol and isopropyl myristate on the in vitro percutaneous penetration of diclofenac sodium from carbopol gels," European Journal of Pharmaceutical Sciences, vol. 7, no. 2, pp. 129-135, 1999.

[9] J. D. Michael, Dermal Toxicology. Toxicologist's Pocket Handbook, CRC Press, 2000.

[10] C. Ren, L. Fang, T. Li, M. Wang, L. Zhao, and Z. He, "Effect of permeation enhancers and organic acids on the skin permeation of indapamide," International Journal of Pharmaceutics, vol. 350, no. 1-2, pp. 43-47, 2008.

[11] R. Jantharaprapap and G. Stagni, "Effects of penetration enhancers on in vitro permeability of meloxicam gels," International Journal of Pharmaceutics, vol. 343, no. 1-2, pp. 26-33, 2007.

[12] S. Santoyo and P. Ygartua, "Effect of skin pretreatment with fatty acids on percutaneous absorption and skin retention of piroxicam after its topical application," European Journal of Pharmaceutics and Biopharmaceutics, vol. 50, no. 2, pp. 245250, 2000.

[13] H. Loth, "Vehicular influence on transdermal drug penetration," International Journal of Pharmaceutics, vol. 68, no. 1-3, pp. 1-10, 1991.

[14] K. Sato, K. Sugibayashi, and Y. Morimoto, "Effect and mode of action of aliphatic esters on the in vitro skin permeation of 
nicorandil," International Journal of Pharmaceutics, vol. 43, no. 1-2, pp. 31-40, 1988.

[15] S. N. Murthy, A. Sen, and S. W. Hui, "Surfactant-enhanced transdermal delivery by electroporation," Journal of Controlled Release, vol. 98, no. 2, pp. 307-315, 2004.

[16] P. Mura, M. T. Faucci, G. Bramanti, and P. Corti, "Evaluation of transcutol as a clonazepam transdermal permeation enhancer from hydrophilic gel formulations," European Journal of Pharmaceutical Sciences, vol. 9, no. 4, pp. 365-372, 2000.

[17] H. O. Ammar, M. Ghorab, S. A. El-Nahhas, and R. Kamel, "Design of a transdermal delivery system for aspirin as an antithrombotic drug," International Journal of Pharmaceutics, vol. 327, no. 1-2, pp. 81-88, 2006.

[18] V. S. N. M. Dwibhashyam and J. Vijaya Ratna, "Chemical penetration enhancers - an update," Indian Drugs, vol. 47, no. 4, pp. 5-18, 2010.

[19] A. N. C. Anigbogu, A. C. Williams, B. W. Barry, and H. G. M. Edwards, "Fourier transform Raman spectroscopy of interactions between the penetration enhancer dimethyl sulfoxide and human stratum corneum," International Journal of Pharmaceutics, vol. 125, no. 2, pp. 265-282, 1995.

[20] P. J. Lee, R. Langer, and V. P. Shastri, "Role of n-methyl pyrrolidone in the enhancement of aqueous phase transdermal transport," Journal of Pharmaceutical Sciences, vol. 94, no. 4, pp. 912-917, 2005. 

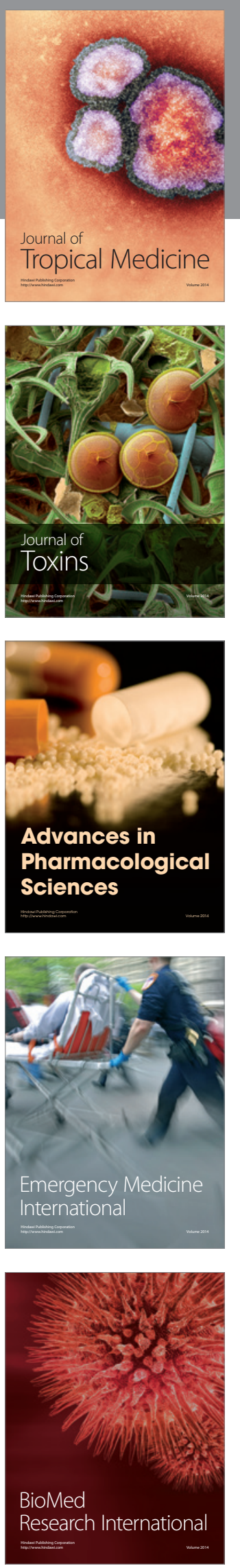
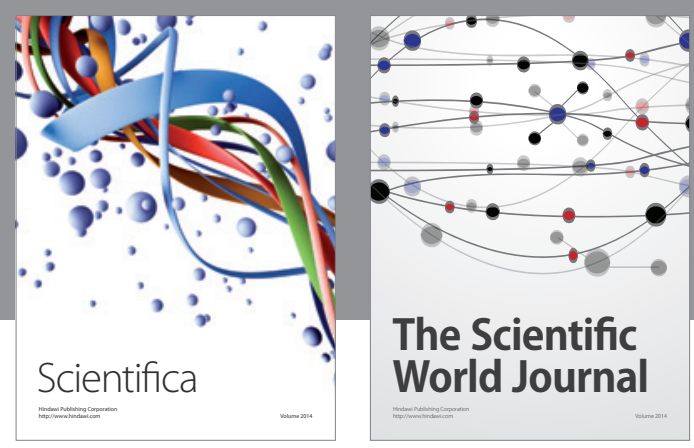

The Scientific World Journal
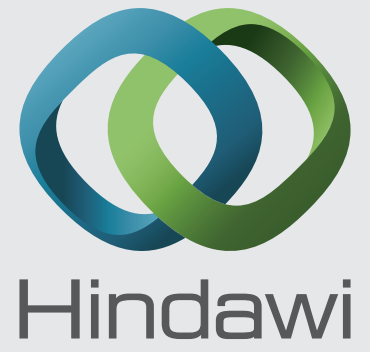

Submit your manuscripts at

http://www.hindawi.com
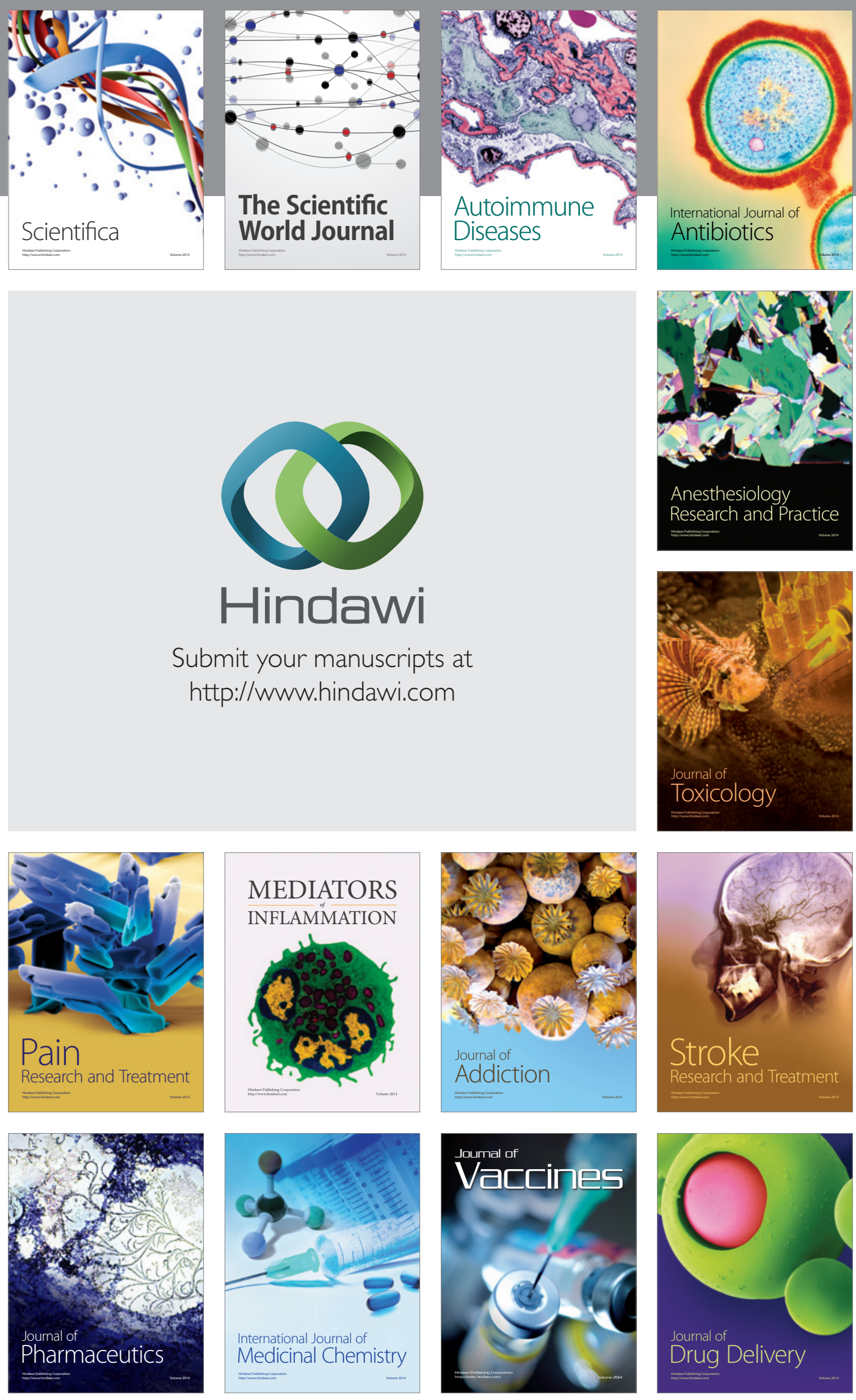